\title{
Socioecology Explains Individual Variation in Urban Space Use in Response to Management in Cape Chacma Baboons (Papio ursinus)
}

\section{Anna M. Bracken, et al. [full author details at the end of the article]}

Received: 14 October 2020 / Accepted: 27 July 2021/ Published online: 18 October 2021

(C) The Author(s) 2021

\begin{abstract}
The presence of wildlife adjacent to and within urban spaces is a growing phenomenon globally. When wildlife's presence in urban spaces has negative impacts for people and wildlife, nonlethal and lethal interventions on animals invariably result. Recent evidence suggests that individuals in wild animal populations vary in both their propensity to use urban space and their response to nonlethal management methods. Understanding such interindividual differences and the drivers of urban space use could help inform management strategies. We use direct observation and high-resolution GPS (1 $\mathrm{Hz}$ ) to track the space use of 13 adult individuals in a group of chacma baboons (Papio ursinus) living at the urban edge in Cape Town, South Africa. The group is managed by a dedicated team of field rangers, who use aversive conditioning to reduce the time spent by the group in urban spaces. Adult males are larger, more assertive, and more inclined to enter houses, and as such are disproportionately subject to "last resort" lethal management. Field rangers therefore focus efforts on curbing the movements of adult males, which, together with high-ranking females and their offspring, comprise the bulk of the group. However, our results reveal that this focus allows low-ranking, socially peripheral female baboons greater access to urban spaces. We suggest that movement of these females into urban spaces, alone or in small groups, is an adaptive response to management interventions, especially given that they have no natural predators. These results highlight the importance of conducting behavioral studies in conjunction with wildlife management, to ensure effective mitigation techniques.
\end{abstract}

Keywords Baboon · Dominance rank · Management - Social cohesion · Urban space use

\section{Introduction}

Urban spaces are growing in size and structure and have complex, powerful direct and indirect effects on ecosystems (Alberti et al., 2003). Species-level adaptations to urban landscapes include flexible behaviors (Chapman et al., 2012; Lowry et al., 2013; Sih

Handling Editor: Joanna M. Setchell. 
et al., 2011), tolerance to a wide variety of habitats (Bonier et al., 2007; Ducatez et al., 2015), and generalist diets (McKinney, 2002). At an individual level, urban space use can vary according to phenotype (Lowry et al., 2013), for example, age and sex (Baker et al., 2007; Dowding et al., 2010; Maibeche et al., 2015; Marty et al., 2019; Merkle et al., 2013). Adult male Barbary macaques (Macaca sylvanus), living in Gouraya National Park that borders the city of Bejaia in Algeria, eat more human foods than females or juveniles (Maibeche et al., 2015), and male American black bears (Ursinus americanus) in Missoula, Montana, use urban spaces more frequently than females and are 1.6 times more likely to be located next to a house (Merkle et al., 2013). Social context and life-history strategies can also drive differences in urban space use (Baranga et al., 2012; Kark et al., 2007). For example, in baboons (Papio spp. excluding Papio hamadryas), male (but not female) dispersal is common (Altmann \& Alberts, 2003; Silk et al., 2003), leading to males being more likely to encounter urban environments (Beamish, 2009). However, detailed investigations of interindividual differences in urban space use are rare, because of the challenges of observing the behavior and movements of many individuals simultaneously (Hughey et al., 2018).

Primates are among the most high-profile species to use urban space (Fehlmann, O'Riain, Kerr-Smith, \& King, 2017b; Hoffman \& O'Riain, 2012b; Klegarth et al., 2017). As innovative problem solvers (Reader \& Laland, 2001) that are adaptable to a variety of environments and diets (Swedell, 2011), they can exploit high-calorie human crops, foods, and waste (Strum, 2010). This urban foraging behavior positively affects time and energy budgets (Fehlmann, O'Riain, Kerr-Smith, \& King, 2017b; van Doorn et al., 2010), resulting in improved body condition for individuals (Strum, 2010) and smaller home ranges for groups (Altmann \& Muruthi, 1988; Hoffman \& O'Riain, 2012a; Strum, 2010). However, use of urban space by primates also has costs and can result in severe injuries or death (Beamish \& O'Riain, 2014) and exposure to crosstransmission of pathogens (Drewe et al., 2012) as a result of their proximity to people.

Contacts and negative interactions with humans are most common among adult males within primate groups (Fuentes \& Gamerl, 2005; Maibeche et al., 2015; Marty et al., 2019; McLennan \& Hockings, 2016; Strum, 2010). It is therefore suggested that management strategies aimed at reducing conflict should focus on adult males (Baranga et al., 2012; Fehlmann, 2017). For example, in the City of Cape Town, South Africa, adult male chacma baboons (Papio ursinus) exploit spaces at the periphery of the city that are close to refuges (Fehlmann, O'Riain, Kerr-Smith, \& King, 2017b), engaging in brief, high-activity "raids" to forage in urban spaces (Fehlmann, O'Riain, Kerr-Smith, Hailes, et al., 2017a) and obtain high-calorie human foods (Kaplan et al., 2011). As a result, "baboon rangers" are employed to deter baboons from urban spaces (Hoffman \& O'Riain, 2012b) and have been successful in reducing negative impacts to people and property (Fehlmann, 2017; van Doorn \& O'Riain, 2020).

Male-focused baboon management can be doubly effective because high-ranking adult males are seen to have a strong influence on group-level movement decisions in different chacma baboon populations (Kaplan et al., 2011; King et al., 2008, 2011; Stueckle \& Zinner, 2008; Sueur, 2011), and group-level urban space use can be significantly reduced by focusing on males in this population (Kaplan et al., 2011). Indeed, males appear to exert a strong influence on movement decisions across baboon species. In olive baboons (Papio anubis) the highest-ranked male is most likely to determine the direction and timing of group movements (Ransom, 1981), in hamadryas 
baboons (Papio hamadryas), males exclusively initiate group movements (Kummer, 1968), and in Guinea baboons (Papio papio), adult males initiate the majority of group departures (Montanari et al., 2019). However, propensity to initiate group movements can be affected by individual, social, and/or environmental factors, and more shared decision-making processes have been observed in olive baboons (Strandburg-Peshkin et al., 2015) as well as female leadership in yellow baboons (Papio cynocephalus) (Norton, 1986).

Here, we study urban space use by a group of baboons ranging in the Da Gama Park region of Cape Town. To better understand interindividual variation in patterns of urban space use, we fitted adults with tracking collars that provided information on their location at high-resolution (1-Hz GPS data). Because adult males are the focus of management (Fehlmann, O'Riain, Kerr-Smith, Hailes, et al., 2017a) and are typically the cause of conflict with people (Beamish, 2009; Fehlmann, O'Riain, Kerr-Smith, Hailes, et al., 2017a), we expected that males, rather than females, would spend more time in the urban space. However, at the start of our study, baboon management reports for the focal group indicated that all baboons were entering the urban space, often in small groups without adult males (Richardson, 2018a, 2018b). We therefore explored the influence of baboon identity and social factors on use of urban space.

\section{Methods}

\section{Study Site and Subjects}

We studied the Da Gama group, which is named after the suburb in which the group ranges: Da Gama Park in the city of Cape Town (Fig. 1a, b). The group comprised 2 adult males, 19 adult females, and approximately 30 subadults, juveniles, and infants. The group's home range includes both urban and natural spaces. Urban spaces encompass two residential suburbs: Da Gama, which is mostly low-income state housing for staff of the South African Navy, and Welcome Glen, a middle-income suburb. The urban environment provides energy-rich food sources (e.g., bread, vegetables, and bird seed) from houses, compost bins, and food waste, as well as from woody plants such as fruiting trees (e.g., guava: Psidium guajava) and Pinus spp. (Fehlmann, O'Riain, Kerr-Smith, Hailes, et al., 2017a; Hoffman \& O’Riain, 2011). The natural habitat is mostly within Table Mountain National Park and is dominated by indigenous fynbos vegetation (Protea, Erica, and Restio spp.) with smaller patches of exotic vegetation (such as Pinus, Acacia, and Eucalyptus spp.) (Hoffman, 2011; van Doorn et al., 2010; van Doorn \& O'Riain, 2020), which comprises the bulk of the baboons' diet when in this habitat (van Doorn et al., 2010). We studied the group from July to November 2018, and here we use data collected mainly during the austral winter (July-September) when our GPS collars were active and when the Peninsula baboons show greater use of urban spaces (van Doorn et al., 2010).

\section{GPS Data}

To obtain information on baboons' space-use patterns, we fitted 16 adults ( 2 males, 14 females) with SHOAL group (Sociality, Heterogeneity, Organisation And Leadership group, based at Swansea University, UK) in-house constructed collars (F2HKv3). 

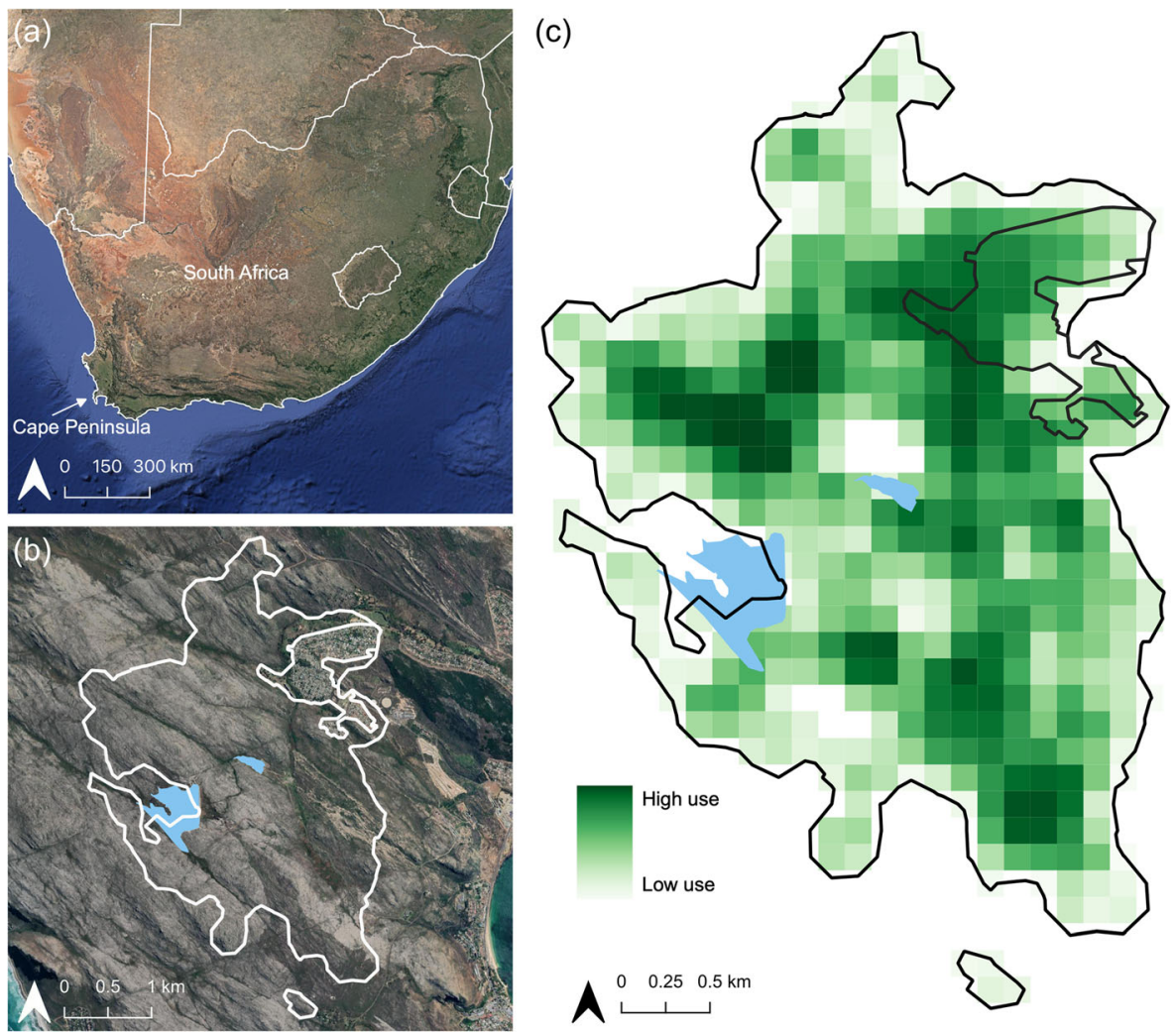

Fig. 1 Study site and baboon group overall space use, between July and September 2018. a The location of the Cape Peninsula in South Africa $(-34.161,18.403)$. b 95\% kernel home range of the baboon group (outer white outline) and the defined urban space (inner white outline). c 95\% kernel home range including the intensity of use, presented within $150 \mathrm{~m} \times 150 \mathrm{~m}$ grid cells, with urban space indicated. Dams are represented as blue areas.

Collars recorded GPS positions at $1 \mathrm{~Hz}$ (1 fix/s) between 08:00 and 20:00 local time (GiPSy 5 tags, TechnoSmArt, Italy). The GPS recording period thus started in the morning after the baboons had left their sleeping site and continued until they had settled at a sleeping site in the evening. Data from 15 collars were retrieved (1 collar was not found after release), and 2 collars failed to record GPS data, resulting in data for 13 baboons ( 2 males, 11 females), for a mean \pm SD of $43 \pm 10$ days, range $=21-54$ days (Electronic Supplementary Material [ESM] Table SI). Data from 13 baboons represented $61 \%$ of all adults in the group and so although we are missing information from several adult females, having 1-Hz GPS data for 2 males and 11 females of different rank for this period of time provides us with an excellent dataset to test our predictions regarding individual differences in urban space use. However, these data come from a single group, with only two males, and therefore making inferences about urban space use by baboons more broadly should be cautioned.

We conducted all analyses in R Studio, version 1.0.153 (R Core Team, 2020). Ad hoc checks of the GPS positional data compared to known landmark locations at the field site in Cape Town and in Swansea, UK, indicated positional accuracy always 
within $5 \mathrm{~m}$. Nevertheless, GPS standalone horizontal position will depend on 1) satellites available, 2) how the collar was positioned on the baboon at any time point, and 3 ) the immediate environment surrounding the collared individual. Therefore, we processed GPS data to remove erroneous fixes 1) by removing relocations outside the study area and 2) by removing successive 1-s GPS fixes between which it would have been impossible for the baboons to travel (i.e., they would have travelled too quickly or would have made an especially large turn). We used two functions as described in Bjørneraas et al. (2010) where outliers are identified as being above a predefined distance threshold from surrounding fixes (here, $250 \mathrm{~m}$ ), or as "spikes" in the trajectory (caused by a high outgoing and/or incoming speed: here, $10 \mathrm{~m} / \mathrm{s}$, or sharp turning angle: here, cosine of turning angle set at $\theta=-0.95$ ) (explained further in Supplementary Methods in the ESM). A median $0.01 \%$ of GPS fixes per collar (range $0.00 \%-$ $0.03 \%$; ESM Table SII) were removed in this manner. Where GPS fixes were missing or had been removed, and where these missing values lasted a time period of less than or equal to $10 \mathrm{~s}$, the path was interpolated using the fixLocNA function in the swaRm package (Garnier, 2016) following O'Bryan et al. (2019). A median $0.02 \%$ of GPS data was interpolated per collar (range $0.00 \%-0.07 \%$; ESM Table SII).

\section{Urban Space Use}

We investigated baboon urban space use at a resolution of $150 \mathrm{~m} \times 150 \mathrm{~m}$ by adding grid cells over the study area in QGIS, version 3.12 (QGIS.org, 2020). We chose this grid cell resolution as the area is larger than the average spread of an individual group in the Cape Peninsula (Hoffman \& O'Riain, 2012a) and is consistent with grid-cell sizes used to investigate space use in this population (Fehlmann, O'Riain, Kerr-Smith, \& King, 2017b), affording comparisons across groups. We delineated the urban space across these grid cells by drawing a polygon around areas dominated by residential buildings and surfaced roads, using Google satellite imagery and OSM standard maps (Fig. 1b). This resulted in 55 urban grid cells.

We calculated urban space use as the intensity of cell use (between 0 and 100, with 0 indicating no use, to 100 indicating complete use) by each collared baboon for each grid cell in the urban space (resulting in $N=55$ measures per baboon) using all available GPS data. We determined intensity of cell use using fixed kernel densities and an ad hoc method for choosing the smoothing parameter, with the function getvolumeUD from the package adehabitat in $\mathrm{R}$ (Calenge, 2006). The baboon group used a variety of sleeping sites throughout their home range, but most frequently slept on top of buildings within the urban space during the period in which GPS receivers were active (52/61 days), particularly on the roof of an apartment block (ESM Fig. S1). This meant that GPS fixes in the urban space during the evening (after the rangers had left) (18:00-20:00, ESM Fig. S2) were associated with the group returning to or being at the urban sleep site. We therefore calculated and reported urban space use based on kernel density estimates using both daytime GPS data (08:00-18:00) and all GPS data (08:00-20:00). We used daytime GPS data when presenting our main results because using all data would overestimate large group sizes in the urban space as all baboons use the sleep site at the same time (ESM Fig. S2). We examined variation in individual baboons' urban space use by subtracting an individual's daytime urban grid cell use 
from the group mean, the result indicating whether an individual used a given cell more or less than the group mean.

To provide context for urban space use, we calculated the number of times one or more baboons entered (and subsequently exited) the urban space polygon using the function getRecursionsInPolygon, Recurse package, R (Bracis et al., 2018). We investigate recursions to provide information on common urban group size (i.e., how frequently urban space is used by all collared baboons or a subset while the rest of the group is outside of urban space). We considered all entries into the polygon to be a recursion, without placing restrictions on recursion duration or interval length between visits. This may overestimate quick visits to the urban space but is likely to reflect true urban group sizes. We also used the MoveVis package (Schwalb-Willmann et al., 2020) in $\mathrm{R}$ to animate examples of baboons entering and exiting urban space (Supplementary Videos).

\section{Dominance Rank}

We calculated baboon dominance hierarchies from observations of aggressive interactions (displacements, chases, and aggressive displays) that were decided following the clear submission of one of the individuals. We recorded these ad libitum by direct observation over 78 days of group follows. We calculated dominance for the 2 males from 75 observations: M1 won 28 interactions (37\%) and M2 won 16 interactions $(21 \%)$, with 31 interactions undecided (41\%). M1 was therefore ranked first. All adult males outrank adult females in chacma baboon groups (Engh et al., 2009; Kitchen et al., 2009). We calculated female rank from 634 interactions (median $=96$, range 11129), using the packages AniDom and Compete in R (Sánchez-Tójar et al., 2018). Full details are provided in Fürtbauer et al. (2020). We standardized ranks between 0 and 1 (with 1 being the highest and 0 the lowest ranking individuals) using the function rescale from the scales package in $\mathrm{R}$ (Wickham, 2014).

\section{Social Cohesion}

To estimate baboon social cohesion, we calculated individual eigenvector centrality scores from proximity-based social networks for daytime minutes during which all collared baboons were outside of the urban polygon, using the package Spatsoc in $\mathrm{R}$ (Robitaille et al., 2019). We chose to remove times inside the urban polygon, as proximity to humans is predicted to alter social networks (Morrow et al., 2019). This resulted in 307,977 minutes in total; mean: 23,690, range: 9743-29683 per individual. Spatial proximity networks have been correlated with other affiliative (i.e., grooming) networks (Cheney et al., 2006; Silk et al., 2003) and provide an association network from which social integration can be derived. We calculated spatial networks by grouping GPS locations temporally (1-min intervals) and then spatially (within $5 \mathrm{~m}$, using the chain rule: Castles et al., 2014), where each GPS fix was buffered by $5 \mathrm{~m}$, and two or more individuals were considered in the same group if they shared a common buffer, even if some of those individuals were not within $5 \mathrm{~m}$ of one another (Peignier et al., 2019; Robitaille et al., 2019). We then converted the grouped data into a group by individual matrix, from which a proximity-based social network was built, using the package asnipe in R (Farine, 2013). We defined the strength of associations between 
dyads of baboons (or network edges) using the simple ratio index (SRI) (Farine \& Whitehead, 2015). From this proximity-based network, we calculated individual eigenvector centrality scores. Eigenvector centrality measures a baboon's importance in the spatial network, while giving consideration to the importance of its neighbors in this network (Farine \& Whitehead, 2015). Because collars recorded data for different lengths of time, we created networks and calculated eigenvector centrality scores for periods during which different numbers of collars (1-13) were recording. We present network analyses using 40 days of synchronous GPS collar data for a time period when $>10$ collars were active ( $>75 \%$ of the collared individuals) in natural areas. These criteria were chosen following a sensitivity analysis (ESM Fig. S3).

\section{Statistical Analyses}

We modeled the difference in urban cell-use by baboons as our response variable, using a Gaussian generalized linear mixed model (GLMM) with a spatial autocorrelation (fitme function in the spaMM package in R: Rousset \& Ferdy, 2014; with a Matérn covariance matrix and maximum likelihood method). To test for the influence of baboon identity on urban space use we fitted individual identity as a random effect, allowing for different intercepts (i.e., interindividual differences) and tested the significance of individual ID using maximum likelihood ratio tests. Additionally, we calculated the intraclass correlation coefficient (ICC) across individuals, using the ICCest function in the ICC package in R (Wolak et al., 2012). To test for the influence of social factors, we considered the effects of dominance rank and eigenvector centrality in the proximity network in the GLMM as fixed effects. Because dominance rank and eigenvector centrality in the proximity network showed a moderate correlation $\left(r_{s}\right.$ : $0.48, P=0.09$ ) we chose to explore their effects in separate models (Suzuki et al., 2008), while controlling for sex (male, female). We selected the best performing model by Akaike information criteria (AIC) using the function get_any_IC in the spaMM package, $\mathrm{R}$ and calculated AIC weights using the function Weights in the MuMIn package, $\mathrm{R}$ (Barton, 2009). We checked model fit using graphical procedures $(Q-Q$ plot and standardized residuals vs. predicted values) using the package DHARMa in R (Hartig, 2020).

\section{Ethical Note}

To fit collars, a veterinarian anesthetized baboons after cage trapping. Cage trapping was organized by Human Wildlife Solutions and conducted according to the Baboon Technical Team's protocols (Hoffman, 2011) as described in the Supplementary Information of Fehlmann, O'Riain, Kerr-Smith, Hailes, et al. (2017a). The use of the collars was approved by Swansea University's Ethics Committee (IP-1314-5). Collars weighed a mean of $2.2 \%$ of baboon body mass (range $1.2 \%-2.6 \%$ ). Collars were fitted with a drop-off mechanism (version CR-7, Telonics, Inc.) to avoid the need for a recapture. The authors declare that there are no conflicts of interest.

Data availability Data required to reproduce our analyses are included as the Electronic Supplementary Material. 


\section{Results}

The urban space represented $13 \%$ of the group's home range (Fig. 1b). During daytime hours baboons spent a mean of $11 \%$ of their time in the urban space (range: $3 \%-26 \% ; N=$ 13 individuals; hours 08:00-18:00; ESM Fig. S4a). If the time baboons were moving to, or were at, their urban sleep site in the evening was included (18:00-20:00), this mean time increased to $21 \%$ (range: $14 \%-34 \% ; \mathrm{n}=13$ individuals; 52/61 GPS days; ESM Fig. S4b).

Using information from when all collars were recording $(N=13)$ during daytime hours (08:00-18:00), we found that baboons entered the urban space alone, or in groups of varying size (median urban group size $=7$, range 113; Fig. 2a; see Video $\mathrm{S} 1$ and Video S2 for animated GPS tracks) and stayed for short periods (median duration $=288$ s, range $1-35,819$ secs; Fig. 2b). If we consider daytime hours when any number of collars were recording and explored the proportion of collared baboons visiting urban space, patterns of space use were qualitatively similar (Fig. 2c, d).

Baboons differed in their use of urban space (Fig. 3a), as shown by the effect of individual identity in our model (GLMM: $\chi^{2}$ LRT $=194.22, P<0.001$ ), and an intraclass correlation coefficient (ICC) of $0.31,95 \%$ CI $0.18-0.55$. Both dominance rank and eigenvector centrality in the proximity network (Fig. 3b, c) predicted variation in urban cell use (Fig. 3d, e) with lower ranking, socially peripheral baboons using urban space more compared to groupmates. A model comparison showed eigenvector network centrality and dominance rank to be comparable when using daytime GPS data
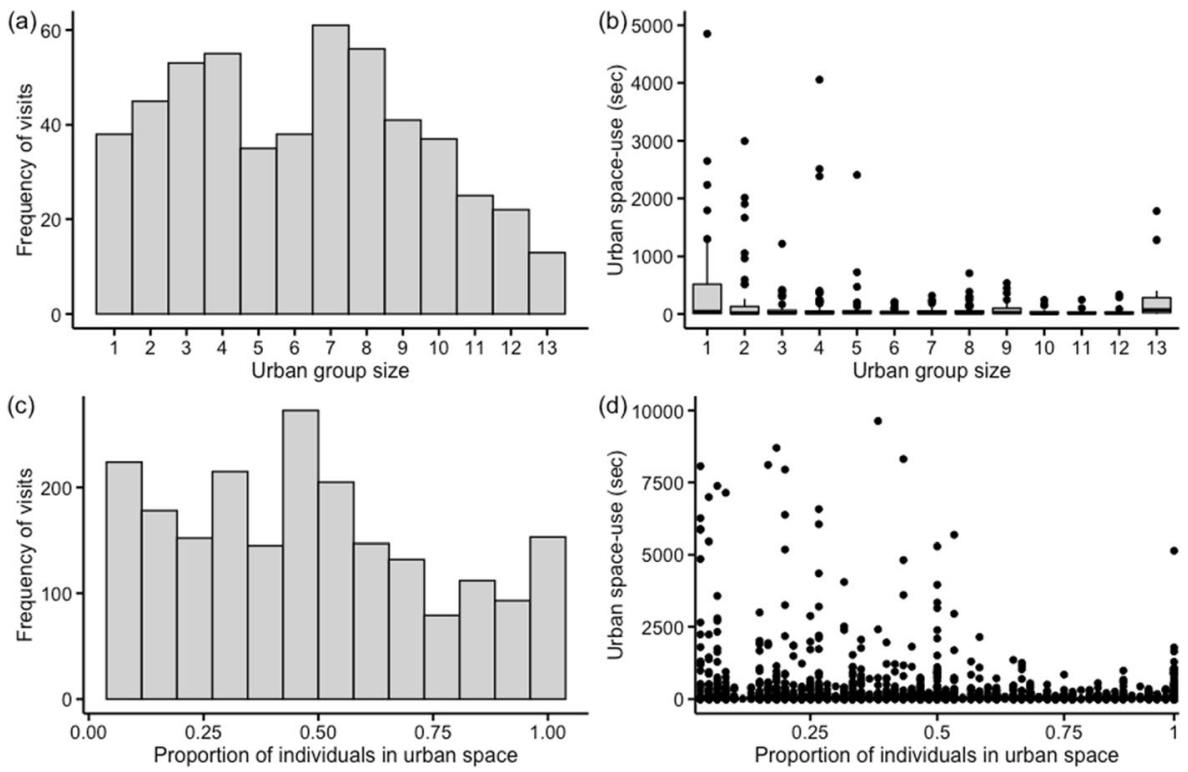

Fig. 2 Urban space use of a baboon group living in Cape Town, South Africa, between July and September 2018. a Frequency of visits to urban space. b Seconds spent in urban space, for different baboon group sizes. c Frequency of visits to urban space as a function of the proportion of collared individuals observed in urban space. d Number of seconds spent in urban space as a function of the proportion of collared individuals observed in urban space. Figures (a) and (b) are based on a time period when all tracking collars $(N=13)$ were recording GPS; figures (c) and (d) are based on all available GPS data, as collars recorded for differing lengths of time. In (b) boxplots indicate median, upper, and lower quartiles, whiskers indicate interquartile ranges, and filled black circles indicate outliers. Note in (b) seven outliers (>5000 s) are not shown. 


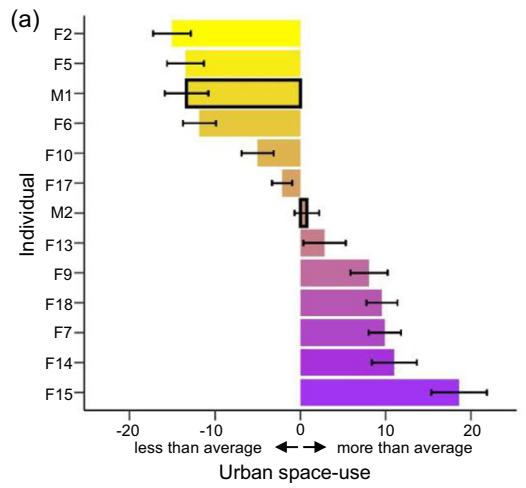

(c)

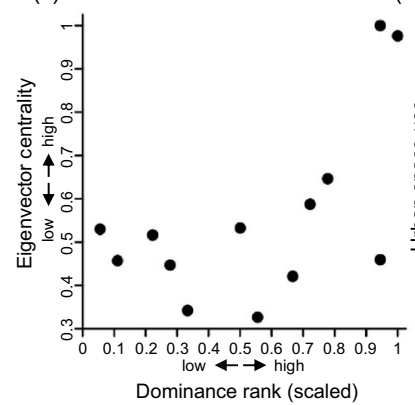

(d)

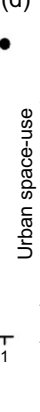

(b)

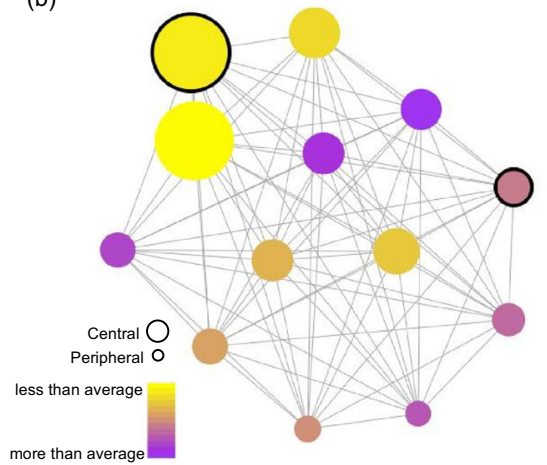

(e)

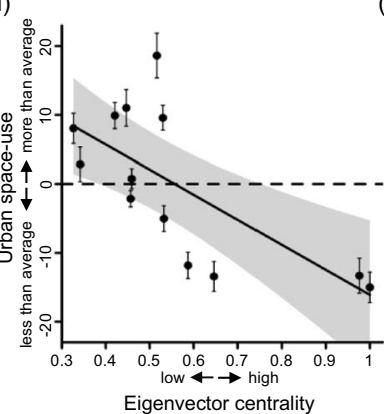

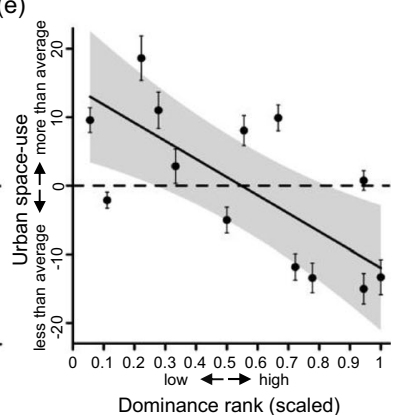

Fig. 3 The influence of social factors on variation in urban space use for a baboon group living in Cape Town, South Africa, between July and September 2018. a Individual mean \pm SE difference in urban cell use. b Baboon social network with increasing circle size indicating higher eigenvector centrality in the group proximity network, and yellow to purple colors representing higher (yellow) or lower (purple) than group mean of urban cell use. $\mathrm{M}$ and $\mathrm{F}$ denote male or female individuals in (a), and two male baboons are represented with black outline in both (a) and (b). c Correlation between dominance rank and eigenvector centrality in the group proximity network. d The influence of baboon eigenvector centrality in the group proximity network on mean $\pm \mathrm{SE}$ individual difference from the group mean of urban cell use. e The influence of baboon dominance rank on mean $\pm \mathrm{SE}$ individual difference from the group mean of urban cell use. For (d) and (e) the black line represents the predicted values, the shaded area represents the confidence intervals using a spaMM model (Rousset \& Ferdy, 2014), and the dashed line represents the group mean of urban cell use, which is set to zero.

(network centrality AIC: 6061.93, AIC weight: 0.564; dominance rank AIC: 6062.45, AIC weight: 0.436 ) and all GPS data (network centrality AIC: 5665.22, AIC weight: 0.393; dominance rank AIC: 5664.34, AIC weight: 0.607) (Supplementary Results). Full model outputs are provided in the Supplementary Information (Table SIII).

\section{Discussion}

Baboon management practice on the Cape Peninsula appears to be minimizing temporal and spatial overlap between the Da Gama baboon group and urban spaces. Our GPS data from 13 adult group members estimates that $13 \%$ of the group's overall home range is urban, with individuals spending a mean of $11 \%$ of their daytime (08:0018:00) in urban spaces. These data contrast favourably with previously recorded use of urban spaces by baboons in managed groups on the Cape Peninsula (e.g., baboons in 
urban spaces for $30 \%$ of all scans: van Doorn \& O'Riain, 2020), but are considerably higher than recent values reported for another Cape Peninsula group, where collared individuals spent a mean of only $1.8 \%$ of time in urban spaces (Fehlmann, O'Riain, Kerr-Smith, Hailes, et al., 2017a). However, this study relied solely on collared adult males; the urban space in which the study was conducted accounted for only $3 \%$ of the overall home range and was buffered by extensive vineyards, which reduced the incentives to forage in urban spaces (Fehlmann, O'Riain, Kerr-Smith, Hailes, et al., 2017a). In contrast, the urban space in the Da Gama group home range transitions abruptly into natural land within Table Mountain National Park. Of concern (from the perspective of baboon management) in the present study is the variation in the way in which individuals use urban spaces during the daytime (range: $3 \%-26 \%$ of total time), because this will mean that different individuals or subgroups of individuals can be in separate places at the same time - both within and outside the urban space - preventing the management of the group as a whole, and consequently splitting the field ranger team into smaller, less effective units.

We found that baboons do not use the urban space equally, adding to the growing evidence that animals adaptively alter their space use in response to human-induced changes to the landscape (Davison et al., 2009; Hamer \& McDonnell, 2008; Roth et al., 2008; Š́lek et al., 2015). In particular, we found females to use the urban space more often than males. Crop-foraging behavior by females in other baboon populations has been explained by their close association with crop-foraging males (Strum, 2010). In the current study population, and in a population in Namibia, chacma baboon alpha males that hold central positions in spatial and grooming networks are more readily followed by others (Kaplan et al., 2011; King et al., 2011), and especially by close affiliates (King et al., 2008). Baboon management therefore focus on deterring adult male baboons from urban spaces (Fehlmann, O'Riain, Kerr-Smith, Hailes, et al., 2017a) and, with them, the rest of the group. So why do baboons still enter the urban space, and frequently in small groups? We suggest that baboon socioecology and management practices together drive the patterns we see in the Da Gama group.

We propose that male-focused management has had two consequences for the Da Gama group. First, the successful implementation of this approach has led to lower urban space-use of the males (and especially the alpha). The second, unintended consequence of rangers focusing on the alpha male and the core of the group (Fehlmann, O'Riain, Kerr-Smith, Hailes, et al., 2017a), in combination with the absence of baboon predators on the Cape Peninsula (Skead, 1980) and the group's relatively large size, is that low-ranking socially peripheral females have been afforded opportunities to temporarily fission and use urban space. Indeed, our analyses show that baboon dominance rank and centrality in the proximity network (which are moderately correlated) both predicted variation in urban space use.

Low-ranked socially peripheral females are afforded more opportunities to use urban space where food rewards are plentiful (van Doorn \& O'Riain, 2020). This may be explained by a variety of factors. Because male baboons are being actively managed away from urban spaces (Fehlmann, O'Riain, Kerr-Smith, Hailes, et al., 2017a), and low-ranked females have weaker affiliation to dominant males (Archie et al., 2014; Palombit et al., 2001), these females are more likely to fission under conflicts of interest (King et al., 2008). Additionally, low-ranked socially peripheral females are often the last to join group movements (King et al., 2011), avoid joining others at foraging 
patches (King et al., 2009), and are likely to be spatially peripheral, affording exploration of novel areas (Kurihara, 2016), the adoption of "producer" foraging tactics (King et al., 2009), and innovative and risky behaviors (Reader \& Laland, 2001). These factors together may drive low-ranked females with low social cohesion to leave the group and access food rewards located in the urban space, rather than remain with the dominant male and his higher-ranking close female affiliates that are generally the primary focus of management (Fehlmann, O'Riain, Kerr-Smith, Hailes, et al., 2017a).

Other case studies also lend support to social factors being important predictors of individuals' use of anthropogenic environments. For instance, the amount of crop foraging by elephants (Loxodonta africana) in Amboseli National Park, Kenya, is predicted by sex and age (where older males are more likely to crop forage), but also by having close associates that crop forage (Chiyo et al., 2012). Studies of primates across species and populations similarly highlight the role of sex and sociality in individuals' use of anthropogenic environments. In three macaque species (Macaca mulatta, Macaca fascicularis, Macaca radiata) across India and Malaysia, males and high-ranking individuals of both sexes had more anthropogenic food in their diets than other individuals (Marty et al., 2019). In moor macaques (Macaca maura), males and individuals with high betweenness centrality in association networks were more often seen on roads and in close proximity to humans (Morrow et al., 2019). A comparative study on 10 periurban macaque groups across three species found that individuals occupying peripheral spatial positions in the group were more likely to interact with humans (Balasubramaniam et al., 2020). The authors suggest this pattern was driven by reduced access to natural forage and increased exposure to human presence for individuals that are peripheral to the group. Overall, this research across different species and contexts highlights how social and ecological factors can interact in complex ways to influence individual behavior and use of urban environments.

The frequent recursions to urban space by individuals and small groups demonstrates high fission-fusion dynamics in the Da Gama group, and these dynamics can lead to a permanent group fission (Sueur et al., 2011), especially when social relationships are constrained at large group sizes (Lehmann et al., 2007). If a permanent fission occurs, this, in effect, creates two groups where there was previously one, and therefore a greater management challenge. In other baboon populations, the exact group size at which fission occurs depends on several factors (Henzi et al., 1997), and on the Cape Peninsula such fissions have previously been observed for a range of group sizes (termed splinter groups: Forthman-Quick, 1986; Strum, 2010). Management of splinter groups is doubly challenging because there is not enough capacity to manage them (i.e., in terms of budget and/or personnel), resulting in increased time in urban spaces compared to managed groups (Hoffman \& O'Riain, 2012b), and urban space use is linked to higher levels of humaninduced injuries and death (Beamish, 2009). Further work is therefore needed to investigate potential ways of limiting the time that solitary and small groups of female baboons spend in urban spaces, thereby also reducing the potential for future fission events and formation of splinter groups.

The City of Cape Town invests approximately R14 million (US \$800 000) per annum on preventing baboons in 10 Peninsula groups from entering urban spaces. We found that small groups of female baboons are breaking away from the main group and spending time in urban spaces. Though adult males may be more noticeable in urban spaces (as they are perceived to be more threatening to humans: Beamish, 2009), individuals from all age-sex 
classes may cause damage to residential buildings, vehicles and bins (Anna M. Bracken and Charlotte Christensen), and therefore the increased use of urban spaces by small groups of females heightens the risk of damage to property and causes difficulties for management (van Doorn \& O'Riain, 2020). Ways in which group size can be constrained in the longer term should be considered, because smaller groups are predicted to be more cohesive (Sueur et al., 2011) and are less likely to fission under conflicts of interest (King et al., 2008), making them easier to manage. One option would be the routine contraception of females, which has been used in captive settings (Plowman et al., 2005). However, contraception also alters the proportion of females in different reproductive states, which impacts behavioral synchrony within chacma baboon groups (King \& Cowlishaw, 2009). Additionally, preliminary data gathered during the current study suggest that females spend less time in urban spaces when they have infants (Bracken et al., unpubl. data.). Constraining group sizes by contraception of females would therefore bring its own management challenges. In the meantime, management should continue to develop other tools to reduce baboon-human conflict, e.g. baboon-proofed fences and baboon-proofing property and bins (see Fehlmann et al., 2020; Hoffman \& O'Riain, 2012a; Kaplan et al., 2011 for discussions). Integrating social sciences research to understand perceptions of individual baboons of different size and sex would further inform management of how and why these low-ranking females have greater access to urban spaces; for example, there may be differences in people's perception of the damage caused, and the threat posed, between male and female baboons (Mormile \& Hill, 2017). Additionally, because local residents are integral to "baboon-proofing" exercises, understanding residents' perceptions of management will inform and promote their success.

In summary, we show that individual baboons can vary greatly in their use of urban spaces, and this can be predicted by social integration; individuals peripheral in the social network are more likely to fission from the group and to use the urban space. Understanding the ways in which group structure influences urban space use is crucial (Baranga et al., 2012), and our results highlight the importance of examining the responses of wildlife to human landscapes at an individual level (Merrick \& Koprowski, 2017). Further work studying individual movement trajectories has the potential to provide greater insight: for example, identifying "keystone" individuals that use urban spaces (King et al., 2018), which may drive an increase (or decrease) in the urban space use of other group members. Additionally, analysis of individual movement can uncover specific behavioral types, such as individuals that are more exploratory or have a higher tendency for risk taking (Merrick \& Koprowski, 2017), and flexibility in these behavioral types (Hertel et al., 2020), which may predict propensity to use urban space. Such approaches are likely to aid management (Merrick \& Koprowski, 2017) by identifying individuals with a large influence on urban space use (King et al., 2018), and incorporating this individual-level information in the development of flexible management tactics. We hope that this work will assist future management decisions involving the Cape baboons and may provide a basis for understanding urban species elsewhere.

Supplementary Information The online version contains supplementary material available at https://doi.org/ 10.1007/s10764-021-00247-x.

Acknowledgments Fieldwork was approved by the Baboon Technical Team (BTT) in the Cape Peninsula and by Research Agreement with South African National Parks (SANParks). Thanks to Human Wildlife Solutions (service providers employed by the City of Cape Town) and veterinarian Dorothy Breed for organizing baboon cage trapping, and to Esme Beamish, and Human Wildlife Solutions for their assistance. 
We thank Lucy Robertson, Charlotte Solman, and Francesca Marshall-Stochmal for assistance with fieldwork. AB thanks Alexis Malagnino for his help and advice with GPS processing and analysis. AJK and IF thank Layla King for support. $\mathrm{AB}$ and $\mathrm{CC}$ were supported by College of Science/Swansea University $\mathrm{PhD}$ scholarships. This research was supported by grants (awarded to AJK) from Swansea University's College of Science and the Association for the Study of Animal Behaviour (ASAB). JO'R was supported by NRF incentive funding. We are grateful to the editor-in-chief Jo Setchell, guest editor Dr Giuseppe Donati, and two anonymous reviewers for constructive feedback during peer review.

Author Contributions $\mathrm{AB}$ and AJK conceived the study with advice from MJO concerning data required to improve adaptive management and the independent assessment of baboon management by professional service providers employed by the City of Cape Town. AB, CC, GF, MDH, and PWH constructed the tracking collars. $\mathrm{AB}$ and $\mathrm{CC}$ collected data in the field. $\mathrm{AB}$ processed and analyzed the data with input from AJK and IF. AB led writing of the manuscript with input from all authors, who read and approved the final manuscript.

Open Access This article is licensed under a Creative Commons Attribution 4.0 International License, which permits use, sharing, adaptation, distribution and reproduction in any medium or format, as long as you give appropriate credit to the original author(s) and the source, provide a link to the Creative Commons licence, and indicate if changes were made. The images or other third party material in this article are included in the article's Creative Commons licence, unless indicated otherwise in a credit line to the material. If material is not included in the article's Creative Commons licence and your intended use is not permitted by statutory regulation or exceeds the permitted use, you will need to obtain permission directly from the copyright holder. To view a copy of this licence, visit http://creativecommons.org/licenses/by/4.0/.

\section{References}

Alberti, M., Marzluff, J. M., Shulenberger, E., Bradley, G., Ryan, C., \& Zumbrunnen, C. (2003). Integrating humans into ecology: Opportunities and challenges for studying urban ecosystems. BioScience, 53, 11691179. https://doi.org/10.1641/0006-3568(2003)053[1169:IHIEOA]2.0.CO;2.

Altmann, J., \& Alberts, S. C. (2003). Variability in reproductive success viewed from a life-history perspective in baboons. American Journal of Human Biology, 15, 401-409. https://doi.org/10.1002/ajhb.10157.

Altmann, J., \& Muruthi, P. (1988). Differences in daily life between semiprovisioned and wild-feeding baboons. American Journal of Primatology, 15, 213-221. https://doi.org/10.1002/ajp.1350150304.

Archie, E. A., Tung, J., Clark, M., Altmann, J., \& Alberts, S. C. (2014). Social affiliation matters: both samesex and opposite-sex relationships predict survival in wild female baboons. Proceedings of the Royal Society B: Biological Sciences, 281, 20141261. https://doi.org/10.1098/rspb.2014.1261.

Baker, P. J., Dowding, C. V., Molony, S. E., White, P. C. L., \& Harris, S. (2007). Activity patterns of urban red foxes (Vulpes vulpes) reduce the risk of traffic-induced mortality. Behavioral Ecology, 18, 716-724. https://oi.org/10.1093/beheco/arm035.

Balasubramaniam, K. N., Marty, P. R., Samartino, S., Sobrino, A., Gill, T., Ismail, M., Saha, R., Beisner, B. A., Kaburu, S. S., \& Bliss-Moreau, E. (2020). Impact of individual demographic and social factors on human-wildlife interactions: A comparative study of three macaque species. Scientific Reports, 10, 1-16. https://doi.org/10.1038/s41598-020-78881-3.

Baranga, D., Basuta, G. I., Teichroeb, J. A., \& Chapman, C. A. (2012). Crop raiding patterns of solitary and social groups of red-tailed monkeys on cocoa pods in Uganda. Tropical Conservation Science, 5, 104 111. https://doi.org/10.1177/194008291200500109.

Barton, K. (2009). Mu-MIn: multi-model inference. R Package Version 1.43.17. http://R-Forge.R-project.org/ projects/mumin/. Accessed April 2021.

Beamish, E. K. (2009). Causes and consequences of mortality and mutilation in the Cape Peninsula baboon population, South Africa. Unpublished master's thesis, University of Cape Town.

Beamish, E. K., \& O'Riain, M. J. (2014). The effects of permanent injury on the behavior and diet of commensal chacma baboons (Papio ursinus) in the Cape Peninsula, South Africa. International Journal of Primatology, 35, 1004-1020. https://doi.org/10.1007/s10764-014-9779-z.

Bjørneraas, K., Van Moorter, B., Rolandsen, C. M., \& Herfindal, I. (2010). Screening global positioning system location data for errors using animal movement characteristics. The Journal of Wildlife Management, 74, 1361-1366 https://doi.org/10.1111/j.1937-2817.2010.tb01258.x. 
Bonier, F., Martin, P. R., \& Wingfield, J. C. (2007). Urban birds have broader environmental tolerance. Biology Letters, 3, 670-673. https://doi.org/10.1098/rsbl.2007.0349.

Bracis, C., Bildstein, K. L., \& Mueller, T. (2018). Revisitation analysis uncovers spatio-temporal patterns in animal movement data. Ecography, 41, 1801-1811. https://oi.org/10.1111/ecog.03618.

Calenge, C. (2006). The package "adehabitat" for the R software: a tool for the analysis of space and habitat use by animals. Ecological Modelling, 197, 516-519. https://doi.org/10.1016/j.ecolmodel.2006.03.017.

Castles, M., Heinsohn, R., Marshall, H. H., Lee, A. E. G., Cowlishaw, G., \& Carter, A. J. (2014). Social networks created with different techniques are not comparable. Animal Behaviour, 96, 59-67. https://doi. org/10.1016/j.anbehav.2014.07.023.

Chapman, T., Rymer, T., \& Pillay, N. (2012). Behavioural correlates of urbanisation in the Cape ground squirrel Xerus inauris. Naturwissenschaften, 99, 893-902. https://doi.org/10.1007/s00114-012-0971-8.

Cheney, D. L., Seyfarth, R. M., Fischer, J., Beehner, J. C., Bergman, T. J., Johnson, S. E., Kitchen, D. M., Palombit, R. A., Rendall, D., \& Silk, J. B. (2006). Reproduction, mortality, and female reproductive success in chacma baboons of the Okavango Delta, Botswana. In L. Swedell \& S. R. Leigh (Eds.), Reproduction and fitness in baboons: Behavioral, ecological, and life history perspectives. Developments in Primatology: Progress and Prospects (pp. 147-176). Springer Science+Business Media.

Chiyo, P. I., Moss, C. J., \& Alberts, S. C. (2012). The influence of life history milestones and association networks on crop-raiding behavior in male African elephants. PLoS ONE, 7, e31382. https://doi.org/10. 1371/journal.pone.0031382.

Davison, J., Huck, M., Delahay, R. J., \& Roper, T. J. (2009). Restricted ranging behaviour in a high-density population of urban badgers. Journal of Zoology, 277, 45-53. https://doi.org/10.1111/j.1469-7998.2008. 00509.x.

Dowding, C. V., Harris, S., Poulton, S., \& Baker, P. J. (2010). Nocturnal ranging behaviour of urban hedgehogs, Erinaceus europaeus, in relation to risk and reward. Animal Behaviour, 80, 13-21. https:// doi.org/10.1016/j.anbehav.2010.04.007.

Drewe, J. A., O’Riain, M. J., Beamish, E., Currie, H., \& Parsons, S. (2012). Survey of infections transmissible between baboons and humans, Cape Town, South Africa. Emerging Infectious Diseases, 18, 298. https:// doi.org/10.3201/eid1802.111309.

Ducatez, S., Clavel, J., \& Lefebvre, L. (2015). Ecological generalism and behavioural innovation in birds: Technical intelligence or the simple incorporation of new foods? Journal of Animal Ecology, 84, 79-89. https://doi.org/10.1111/1365-2656.12255.

Engh, A. L., Hoffmeier, R. R., Seyfarth, R. M., \& Cheney, D. L. (2009). O brother, where art thou? The varying influence of older siblings in rank acquisition by female baboons. Behavioral Ecology and Sociobiology, 64, 97-104. https://doi.org/10.1007/s00265-009-0824-4.

Farine, D. R. (2013). Animal social network inference and permutations for ecologists in R using asnipe. Methods in Ecology and Evolution, 4, 1187-1194. https://doi.org/10.1111/2041-210X.12121.

Farine, D. R., \& Whitehead, H. (2015). Constructing, conducting and interpreting animal social network analysis. Journal of Animal Ecology, 84, 1144-1163. https://doi.org/10.1111/1365-2656.12418.

Fehlmann, G. (2017). Understanding baboon behavioural ecology in a human altered landscape. Unpublished doctoral thesis, Swansea University.

Fehlmann, G., O'Riain, M. J., Kerr-Smith, C., Hailes, S., Luckman, A., Shepard, E. L. C., \& King, A. J. (2017a). Extreme behavioural shifts by baboons exploiting risky, resource-rich, human-modified environments. Scientific Reports, 7, 15057. https://doi.org/10.1038/s41598-017-14871-2.

Fehlmann, G., O'Riain, M. J., Kerr-Smith, C., \& King, A. J. (2017b). Adaptive space use by baboons (Papio ursinus) in response to management interventions in a human-changed landscape. Animal Conservation, 20, 101-109. https://doi.org/10.1111/acv.12293.

Fehlmann, G., O’Riain, M. J., Fürtbauer, I., \& King, A. J. (2020). Behavioral causes, ecological consequences, and management challenges associated with wildlife foraging in human-modified landscapes. BioScience, 71, 40-54. https://doi.org/10.1093/biosci/biaa129.

Forthman-Quick, D. L. (1986). Activity budgets and the consumption of human foods in two troops of baboons, Papio anubis, at Gilgil, Kenya. In J. C. Else \& P. C. Lee (Eds.), Primate ecology and conservation (pp. 221-228). Cambridge University Press.

Fuentes, A., \& Gamerl, S. (2005). Disproportionate participation by age/sex classes in aggressive interactions between long-tailed macaques (Macaca fascicularis) and human tourists at Padangtegal monkey forest, Bali, Indonesia. American Journal of Primatology, 66, 197-204. https://doi.org/10.1002/ajp.20138.

Fürtbauer, I., Christensen, C., Bracken, A., O'Riain, M. J., Heistermann, M., \& King, A. J. (2020). Energetics at the urban edge: Environmental and individual predictors of urinary C-peptide levels in wild chacma baboons (Papio ursinus). Hormones and Behavior, 126, 104846. https://doi.org/10.1016/j.yhbeh.2020. 104846 . 
Garnier, S. (2016). SwaRm. https://github.com/swarm-lab/swaRm. Accessed May 2019.

Hamer, A. J., \& McDonnell, M. J. (2008). Amphibian ecology and conservation in the urbanising world: A review. Biological Conservation, 141, 2432-2449. https://doi.org/10.1016/j.biocon.2008.07.020.

Hartig, F. (2020). DHARMa: Residual diagnostics for hierarchical (multi-level/mixed) regression models. R package version 0.3.3.0. http://florianhartig.github.io/DHARMa. Accessed May 2020.

Henzi, S., Lycett, J., \& Piper, S. (1997). Fission and troop size in a mountain baboon population. Animal Behaviour, 53, 525-535. https://doi.org/10.1006/anbe.1996.0302.

Hertel, A. G., Niemelä, P. T., Dingemanse, N. J., \& Mueller, T. (2020). A guide for studying amongindividual behavioral variation from movement data in the wild. Movement Ecology, 8, 1-18. https://doi. org/10.1186/s40462-020-00216-8.

Hoffman, T. S. (2011). The spatial ecology of chacma baboons (Papio ursinus) in the Cape Peninusula, South Africa: Towards improved management and conservation strategies. Unpublished doctoral thesis, University of Cape Town.

Hoffman, T. S., \& O'Riain, M. J. (2011). The spatial ecology of chacma baboons (Papio ursinus) in a humanmodified environment. International Journal of Primatology, 32, 308-328. https://doi.org/10.1007/ s10764-010-9467-6.

Hoffman, T. S., \& O'Riain, M. J. (2012a). Landscape requirements of a primate population in a humandominated environment. Frontiers in Zoology, 9, 1. https://doi.org/10.1186/1742-9994-9-1.

Hoffman, T. S., \& O'Riain, M. J. (2012b). Monkey management: using spatial ecology to understand the extent and severity of human-baboon conflict in the Cape Peninsula, South Africa. Ecology and Society, 17, 13. https://doi.org/10.5751/ES-04882-170313.

Hughey, L. F., Hein, A. M., Strandburg-Peshkin, A., \& Jensen, F. H. (2018). Challenges and solutions for studying collective animal behaviour in the wild. Philosophical Transactions of the Royal Society B: Biological Sciences, 373, 20170005. https://doi.org/10.1098/rstb.2017.0005.

Kaplan, B. S., O’Riain, M. J., van Eeden, R., \& King, A. J. (2011). A low-cost manipulation of food resources reduces spatial overlap between baboons (Papio ursinus) and humans in conflict. International Journal of Primatology, 32, 1397-1412. https://doi.org/10.1007/s10764-011-9541-8.

Kark, S., Iwaniuk, A., Schalimtzek, A., \& Banker, E. (2007). Living in the city: Can anyone become an 'urban exploiter'? Journal of Biogeography, 34, 638-651. https://doi.org/10.1111/j.1365-2699.2006.01638.x.

King, A. J., \& Cowlishaw, G. (2009). All together now: Behavioural synchrony in baboons. Animal Behaviour, 78, 1381-1387. https://doi.org/10.1016/j.anbehav.2009.09.009.

King, A. J., Douglas, C. M. S., Huchard, E., Isaac, N. J. B., \& Cowlishaw, G. (2008). Dominance and affiliation mediate despotism in a social primate. Current Biology, 18, 1833-1838. https://doi.org/10. 1016/j.cub.2008.10.048.

King, A. J., Isaac, N. J. B., \& Cowlishaw, G. (2009). Ecological, social, and reproductive factors shape producer-scrounger dynamics in baboons. Behavioral Ecology, 20, 1039-1049. https://doi.org/10.1093/ beheco/arp095.

King, A. J., Sueur, C., Huchard, E., \& Cowlishaw, G. (2011). A rule-of-thumb based on social affiliation explains collective movements in desert baboons. Animal Behaviour, 82, 1337-1345. https://doi.org/10. 1016/j.anbehav.2011.09.017.

King, A. J., Fehlmann, G., Biro, D., Ward, A. J., \& Fürtbauer, I. (2018). Re-wilding collective behaviour: An ecological perspective. Trends in Ecology \& Evolution, 33, 347-357. https://doi.org/10.1016/j.tree.2018. 03.004.

Kitchen, D. M., Beehner, J. C., Bergman, T. J., Cheney, D. L., Crockford, C., Engh, A. L., Fischer, J., Seyfarth, R. M., \& Wittig, R. (2009). The causes and consequences of male aggression directed at female chacma baboons. In M. N. Muller \& R. W. Wrangham (Eds.), Sexual coercion in primates and humans: An evolutionary perspective on male aggression against females (pp. 128-156). Harvard University Press.

Klegarth, A. R., Hollocher, H., Jones-Engel, L., Shaw, E., Lee, B. P. Y. H., Feeney, T., Holmes, D., Laguea, D., \& Fuentes, A. (2017). Urban primate ranging patterns: GPS-collar deployments for Macaca fascicularis and M. sylvanus. American Journal of Primatology, 79, e22633. https://doi.org/10.1002/ ajp. 22633.

Kummer, H. (1968). Social organization of hamadryas baboons: A field study. The University of Chicago Press.

Kurihara, Y. (2016). Low-ranking female Japanese macaques make efforts for social grooming. Current Zoology, 62, 99-108. https://doi.org/10.1093/cz/zow006.

Lehmann, J., Korstjens, A. H., \& Dunbar, R. I. M. (2007). Group size, grooming and social cohesion in primates. Animal Behaviour, 74, 1617-1629. https://doi.org/10.1016/j.anbehav.2006.10.025. 
Lowry, H., Lill, A., \& Wong, B. B. M. (2013). Behavioural responses of wildlife to urban environments. Biological Reviews, 88, 537-549. https://doi.org/10.1111/brv.12012.

Maibeche, Y., Moali, A., Yahi, N., \& Menard, N. (2015). Is diet flexibility an adaptive life trait for relictual and peri-urban populations of the endangered primate Macaca sylvanus? PloS ONE, 10, e0118596. https://doi.org/10.1371/journal.pone.0118596.

Marty, P. R., Balasubramaniam, K. N., Kaburu, S. S. K., Hubbard, J., Beisner, B., Bliss-Moreau, E., Ruppert, N., Arlet, M. E., Sah, S. A. M., \& Ismail, A. (2019). Individuals in urban dwelling primate species face unequal benefits associated with living in an anthropogenic environment. Primates, 61, 1-7. https://doi. org/10.1007/s10329-019-00775-4.

McKinney, M. L. (2002). Urbanization, biodiversity, and conservation: The impacts of urbanization on native species are poorly studied, but educating a highly urbanized human population about these impacts can greatly improve species conservation in all ecosystems. Bioscience, 52, 883-890. https://doi.org/10.1641/ 0006-3568(2002)052[0883:UBAC]2.0.CO;2.

McLennan, M. R., \& Hockings, K. J. (2016). The aggressive apes? Causes and contexts of great ape attacks on local persons. In F. Angelici (Ed.), Problematic wildlife (pp. 373-394). Springer.

Merkle, J. A., Robinson, H. S., Krausman, P. R., \& Alaback, P. (2013). Food availability and foraging near human developments by black bears. Journal of Mammalogy, 94, 378-385. https://doi.org/10.1644/12MAMM-A-002.1.

Merrick, M. J., \& Koprowski, J. L. (2017). Should we consider individual behavior differences in applied wildlife conservation studies? Biological Conservation, 209, 34-44. https://doi.org/10.1016/j.biocon. 2017.01.021.

Montanari, D., Hambuckers, J., Fischer, J., \& Zinner, D. (2019). Coordination during group departures and group progressions in the tolerant multilevel society of wild Guinea baboons (Papio papio). BioRxiv, 797761. https://doi.org/10.1101/797761.

Mormile, J. E., \& Hill, C. M. (2017). Living with urban baboons: Exploring attitudes and their implications for local baboon conservation and management in Knysna, South Africa. Human Dimensions of Wildlife, 22, 99-109. https://doi.org/10.1080/10871209.2016.1255919.

Morrow, K. S., Glanz, H., Ngakan, P. O., \& Riley, E. P. (2019). Interactions with humans are jointly influenced by life history stage and social network factors and reduce group cohesion in moor macaques (Macaca maura). Scientific Reports, 9, 1-12. https://doi.org/10.1038/s41598-019-56288-z.

Norton, G. W. (1986). Leadership: Decision processes of group movement in yellow baboons. In J. C. Else \& P. C. Lee (Eds.), Primate ecology and conservation (pp. 145-156). Cambridge University Press.

O'Bryan, L. R., Abaid, N., Nakayama, S., Dey, T., King, A. J., Cowlishaw, G., Rubenstein, D. I., \& Garnier, S. (2019). Contact calls facilitate group contraction in free-ranging goats (Capra aegagrus hircus). Frontiers in Ecology and Evolution, 7, 73. https://doi.org/10.3389/fevo.2019.00073.

Palombit, R. A., Cheney, D. L., \& Seyfarth, R. M. (2001). Female-female competition for male 'friends' in wild chacma baboons (Papio cynocephalus ursinus). Animal Behaviour, 61, 1159-1171. https://doi.org/ 10.1006/anbe.2000.1690.

Peignier, M., Webber, Q. M. R., Koen, E. L., Laforge, M. P., Robitaille, A. L., \& Vander Wal, E. (2019). Space use and social association in a gregarious ungulate: Testing the conspecific attraction and resource dispersion hypotheses. Ecology and Evolution, 9, 5133-5145. https://doi.org/10.1002/ece3.5071.

Plowman, A. B., Jordan, N. R., Anderson, N., Condon, E., \& Fraser, O. (2005). Welfare implications of captive primate population management: Behavioural and psycho-social effects of female-based contraception, oestrus and male removal in hamadryas baboons (Papio hamadryas). Applied Animal Behaviour Science, 90, 155-165. https://doi.org/10.1016/j.applanim.2004.08.014.

QGIS.org. (2020). QGIS Geographic Information System. Open Source Geospatial Foundation Project. http:// qgis.osgeo.org.

R Core Team. (2020). R: A language and environment for statistical computing. R Foundation for Statistical Computing, Vienna, Austria. https://www.R-project.org/.

Ransom, T. W. (1981). Beach troop of the Gombe. Associated University Presses.

Reader, S. M., \& Laland, K. N. (2001). Primate innovation: Sex, age and social rank differences. International Journal of Primatology, 22, 787-805. https://doi.org/10.1023/A:1012069500899.

Richardson, P. (2018a). HWS monthly report, July. https://hwsolutions.co.za/wp-content/uploads/2018/09/ HWS-Monthly-Report-JULY-2018.pdf. Accessed August 2020.

Richardson, P. (2018b). HWS monthly report, June. https://hwsolutions.co.za/wp-content/uploads/2018/07/ HWS-Monthly-Report-June-2018.pdf. Accessed August 2020.

Robitaille, A. L., Webber, Q. M. R., \& Vander Wal, E. (2019). Conducting social network analysis with animal telemetry data: Applications and methods using spatsoc. Methods in Ecology and Evolution, 10, 1203-1211. https://doi.org/10.1111/2041-210X.13215. 
Roth, T. C., Vetter, W. E., \& Lima, S. L. (2008). Spatial ecology of winting Accipiter hawks: Home range, habitat use, and the influence of bird feeders. The Condor, 110, 260-268. https://doi.org/10.1525/cond. 2008.8489.

Rousset, F., \& Ferdy, J. B. (2014). Testing environmental and genetic effects in the presence of spatial autocorrelation. Ecography, 37, 781-790. https://doi.org/10.1111/ecog.00566.

Š́lek, M., Drahníková, L., \& Tkadlec, E. (2015). Changes in home range sizes and population densities of carnivore species along the natural to urban habitat gradient. Mammal Review, 45, 1-14. https://doi.org/ 10.1111/mam.12027.

Sánchez-Tójar, A., Schroeder, J., \& Farine, D. R. (2018). A practical guide for inferring reliable dominance hierarchies and estimating their uncertainty. Journal of Animal Ecology, 87, 594-608. https://doi.org/10. 1111/1365-2656.12776.

Schwalb-Willmann, J., Remelgado, R., Safi, K., \& Wegmann, M. (2020). moveVis: Animating movement trajectories in synchronicity with static or temporally dynamic environmental data in R. Methods in Ecology and Evolution, 11, 664-669. https://doi.org/10.1111/2041-210X.13374.

Sih, A., Ferrari, M. C. O., \& Harris, D. J. (2011). Evolution and behavioural responses to human-induced rapid environmental change. Evolutionary Applications, 4, 367-387. https://doi.org/10.1111/j.1752-4571.2010. 00166.x.

Silk, J. B., Alberts, S. C., \& Altmann, J. (2003). Social bonds of female baboons enhance infant survival. Science, 302, 1231-1234. https://doi.org/10.1126/science.1088580.

Skead, C. J. (1980). Historical mammal incidence in the Cape Province (Vol. 1): Cape Town, The Department of Nature and Environmental Conservation of the Provincial Administration of the Cape of Good Hope.

Strandburg-Peshkin, A., Farine, D. R., Couzin, I. D., \& Crofoot, M. C. (2015). Shared decision-making drives collective movement in wild baboons. Science, 348, 1358-1361. https://doi.org/10.1126/science.aaa5099.

Strum, S. C. (2010). The development of primate raiding: Implications for management and conservation. International Journal of Primatology, 31, 133-156. https://doi.org/10.1007/s10764-009-9387-5.

Stueckle, S., \& Zinner, D. (2008). To follow or not to follow: Decision making and leadership during the morning departure in chacma baboons. Animal Behaviour, 75, 1995-2004. https://doi.org/10.1016/j. anbehav.2007.12.012.

Sueur, C. (2011). Group decision-making in chacma baboons: Leadership, order and communication during movement. BMC ecology, 11, 1-14. https://doi.org/10.1186/1472-6785-11-26.

Sueur, C., Deneubourg, J.-L., Petit, O., \& Couzin, I. D. (2011). Group size, grooming and fission in primates: A modeling approach based on group structure. Journal of Theoretical Biology, 273, 156-166. https://doi. org/10.1016/j.jtbi.2010.12.035.

Suzuki, N., Olson, D. H., \& Reilly, E. C. (2008). Developing landscape habitat models for rare amphibians with small geographic ranges: A case study of Siskiyou Mountains salamanders in the western USA. Biodiversity and Conservation, 17, 2197-2218. https://doi.org/10.1007/s10531-007-9281-4.

Swedell, L. (2011). African papionins: Diversity of social organization and ecological flexibility. In C. J. Campbell, A. Fuentes, K. C. MacKinnon, S. K. Bearder, \& R. M. Stumpf (Eds.), Primates in perspective (2nd ed., pp. 241-277). Oxford University Press.

van Doorn, A. C., \& O'Riain, M. J. (2020). Nonlethal management of baboons on the urban edge of a large metropole. American Journal of Primatology, 82, e23164. https://doi.org/10.1002/ajp.23164.

van Doorn, A. C., O'Riain, M. J., \& Swedell, L. (2010). The effects of extreme seasonality of climate and day length on the activity budget and diet of semi-commensal chacma baboons (Papio ursinus) in the Cape Peninsula of South Africa. American Journal of Primatology, 72, 104-112. https://doi.org/10.1002/ajp. 20759.

Wickham, H. (2014). Package 'scales': Scale functions for visualization. https:/cran.r-project.org/web/ packages/scales/scales.pdf. Accessed June 2019.

Wolak, M. E., Fairbairn, D. J., \& Paulsen, Y. R. (2012). Guidelines for estimating repeatability. Methods in Ecology and Evolution, 3, 129-137. https://doi.org/10.1111/j.2041-210X.2011.00125.x. 


\section{Affiliations}

Anna M. Bracken ${ }^{1}$ • Charlotte Christensen ${ }^{1}$ • M. Justin O'Riain ${ }^{2} \cdot$ Gaëlle Fehlmann $^{1,3}$ - Mark D. Holton ${ }^{1,4}$. Phil W. Hopkins ${ }^{4}$ - Ines Fürtbauer ${ }^{1}$ - Andrew J. King ${ }^{1}$

$\triangle$ Anna M. Bracken

967936@swansea.ac.uk

1 Department of Biosciences, College of Science, Swansea University, Swansea, UK

2 Department of Biological Sciences, Institute for Communities and Wildlife in Africa, University of Cape Town, Cape Town, South Africa

3 Present address: Cognitive and Cultural Ecology Group, Max Planck Institute of Animal Behavior, Radolfzell, Germany

4 College of Science, Swansea University, Swansea, UK 